ORIGINAL ARTICLE

\title{
Frequency of noise induced hearing loss and its association with anxiety in textile mill workers.
}

\author{
Azmat Tahira ${ }^{1}$, Atia-Ur-Rehman², Tahira Ashraf ${ }^{3}$, Waris Ali $^{4}$, Ambreen Sadaf $^{5}$, Taimoor Hassan ${ }^{6}$
}

Article Citation: Tahira A, Atia-Ur-Rehman, Ashraf T, Ali W, Sadaf A, Hassan T. Frequency of noise induced hearing loss and its association with anxiety in textile mill workers. Professional Med J 2022; 29(2):160-166. https://doi.org/10.29309/TPMJ/2022.29.02.6482

\begin{abstract}
Objective: To find out frequency of noise induced hearing loss and its association with anxiety in textile mill workers. Study Design: Analytical Cross-sectional study. Setting: Master Textile Mill's Spinning and Weaving Units. Pvt. Ltd. Lahore. Period: December 2019 to May 2020. Material \& Methods: An analytical cross-sectional study was conducted on 125 textile mill workers with non-probability purposive sampling having 5 to 10 years working experience in spinning and weaving units of age 25 to 40 years (males). Data was collected by performing Otoscopy, tympanometry and pure tone audiometry in noise-controlled room and BAl, analyzed and evaluated with the help of statistical package for social sciences version 25.00. Pearson chi square was used and $P$ value was equal or less than $5 \%$ was taken as significant. Results: Total number of 125 (100\%) were tested to check their hearing levels by standard pure tone audiometry. Out of 125(100\%) 14(11.2 $\%)$ were with normal hearing. 28(22.4\%) with mild hearing, 36(29\%) with mild to moderate hearing, 34(27\%) with moderate hearing, $12(10 \%)$ with moderately severe hearing and $1(0.8 \%)$ with severe hearing levels. Out of $125(100 \%) 50(40 \%)$ were diagnosed with low level of anxiety, 43(34\%) were with moderate level of anxiety and $32(26 \%)$ were with severe level of anxiety in all the participants working in the textile mill. Conclusion: It is concluded that the mill workers are on the risk of developing hearing loss of different severity levels which also cause anxiety to them.
\end{abstract}

Key words: $\quad$ Anxiety, Carhart Notch, Noise Induced Hearing Loss, Occupational Noise, Pure Tone Audiometry.

\section{INTRODUCTION}

Hearing impairment is a natural ageing as well as the most common reason of disability in the world. Around 1 in 4 adults at 45 years of age have medium or higher hearing loss. ${ }^{1} 360$ million people identified by the World Health Organization suffered from impaired hearing loss, around $5.3 \%$ of the population of the planet. $^{2}$ Anxiety is a widespread psychiatric illness affecting 350 million people worldwide. Hearing loss can increase the worsening of health quality of life and damaged hearing, which can lead to social behavior, anxiety, interpersonal vulnerability and conflicts for the affected individuals. Several cross-sectional studies have shown that anxiety in the elderly population triggers hearing loss independently. Some studies have, however, reported contradictory findings. ${ }^{4}$ The clear correlation between hearing loss and anxiety in adults of all ages in the United States was confirmed by a nationwide survey. Hearing impairment was the 13th most important contributor to the global disease burden in 2002 and is estimated to contribute ninth worldwide and seventh in highincome countries by $2030 .{ }^{5} 12.7 \%$ of people over the age of 12 are reported to be impacted in the United States alone. Considering the importance of global and national hearing loss, it is important to recognize its social effects. ${ }^{6}$

Hearing damage due to workplace noise sensitivity leads to a crippling handicap that is nearly $100 \%$ preventable. The second most frequent source of sensorineural Hearing loss is a noise-induced loss of hearing. Excess noises pose a global health hazard to the workplace, including noise caused hearing loss (NIHL), with significant social and physiologic consequences. ${ }^{7}$
1. MS (Hearing Sciences), Senior Lecturer Health Professional Technologies, The University of Lahore.

2. Ph.D (Scholar), Assistant Professor/ DHPT (AHS), The University of Lahore.

3. Ph.D (Rehabilitation Sciences), Assistant Professor/ DHPT (AHS), The University of Lahore.

4. MS (Hearing Sciences), Clinical Audiologist, Hameed Latif Hospital Lahore.

5. MS Scholar Clinical Psychology, Demonstrator, The University of Lahore.

6. Bachelor Operation Theater Sciences, Lecturer Health Professional Technologies, The University of Lahore, Pakistan.
Correspondence Address:
Dr. Taimoor Hassan
Department of Health Professional
Technologies
The University of Lahore, Pakistan.
taimoorhassan408.th@gmail.com

Article received on:

$18 / 03 / 2021$

Accepted for publication: 
Excessive noise is an omnipresent occupational risk with many negative effects, including high blood pressure reduction, sleep discomfort, irritation and stress, tinnitus, $\mathrm{NIHL}$, and transient threshold increase. ${ }^{8}$ Among these, NIHL's most significant health impact is caused by permanent damage to sensitive inner ear hearing systems. NIHL normally requires the frequency (pitch) spectrum human voices and thus interferes with the words spoken. ${ }^{9}$ Sharp forces from any sound affect the stereocyanism the cochlea basil membrane's hair cells, and can cause cell death by excessive forces. ${ }^{10}$ Avoiding noise exposure avoids additional damage. Hearing loss for adults was described as 15th gravest health problem in the world," with profound consequences ranging from social division and individual stigmatization to severe national economic burdens. ${ }^{11}$ An estimated 120 million to 360 million people worldwide have been affected by hearing loss. ${ }^{12}$ Noise is the pervasive cause of all industrial toxins which affect all industries in all countries of the world and cause severe hearing problems. The major preventable cause of irreversible hearing loss is excessive noise exposure. ${ }^{13}$

In the nation, 16 per cent of the affected hearing loss in adults in the different sub-regions is due to workplace noise. In developed countries, the average noise burden differs between 0.2 and 2 percent of GDP. Human cochlea can perceive frequencies from $20 \mathrm{~Hz}$ to $20000 \mathrm{~Hz}$, $125 \mathrm{~Hz}$ to $8000 \mathrm{~Hz}$ on audiometry called speech frequencies. High frequencies than middle and low frequencies have workplace noise consequences. Symmetrical bilateral Noise induced hearing loss (NIHL) is affecting typically the higher frequencies and then the lower frequencies of the noise $(0,5 k, 1 k$ or $2 k \mathrm{~Hz})$. Failure to focus, irritate, tiredness, fatigue, sleep disturbances are other significant health consequences. The key industries that cause excessive noise and expose workers to harmful noise are textiles, printing, slag mills, mining, etc. ${ }^{14}$ Most of this condition can be caused by occupational noise exposure. Noise loss is a senso-neuronal hearing disorder, beginning at high frequencies $(3000-6000 \mathrm{~Hz})$ and increasing steadily because of the frequency of sound exposure. Although the losses are typically symmetrical, sources such as arms or sirens may cause asymmetrical loss. The acute impulse noise exposure result is acoustic shock, a related condition. The main cause of hearing issues is the excessive noise tolerance. There is an approximate risk of noise-induced hearing disorders for up to 500 million people worldwide. ${ }^{15}$

The main goal of this study is toward establishing the relation among hearing loss caused by noise and anxiety. Noise is a leading cause of hearing damage. The noise-induced hearing loss and association with anxiety exists in unusual local literature and literature. In Pakistan, relatively little attention was paid to hearing loss caused by noise and its effects. In Pakistan, noise psychological problems have always been ignored. The association between anxiety and hearing loss must therefore be acknowledged. This research was therefore designed to fill this literature void and to find local data on noise level and its anxiety relation.

\section{MATERIAL \& METHODS}

This analytical cross-sectional study was carried out in Master textile mill's spinning and weaving units Pvt. Ltd. Lahore for a period of six months from December 2019 to May 2020. Total 125 workers participated in this study. Nonprobability sampling technique was applied. All male workers having 5 to 10 years of working experience between the age range of 25 to 40 years were included in this study. All others cases of co morbidities which can result hearing loss and anxiety were excluded from the study. Otoscope, Tympanometry, Standard Pure tone audiometer and Beck anxiety inventory were used for assessment. Otoscope is an instrument by which we examine the outer and middle ear to rule out any kind of ailment while Tympanometer is an instrument which is used to check the middle ear status i.e middle ear pressure, compliance and ear canal volume. And audiometer is an instrument which is used to determine the degree and type of hearing loss. Data was collected by performing Otoscopy, tympanometry and pure tone audiometry in noise-controlled room, analyzed and evaluated with the help of statistical package for social sciences version 25.00. 
Pearson chi square was used and $P$ value was equal or less than $5 \%$ was taken as significant. Ethical approval was taken from the Institutional Review Board (IRB-UOL-FAHS/678/2019).

\section{RESULTS}

Table-I shows Total number of $125(100 \%)$ were tested to check their hearing levels by standard pure tone audiometer. Out of $12514(11.2 \%)$ were with normal hearing. 28(22.4\%) with mild hearing levels, 36(29\%) with mild to moderate hearing levels, 34(27\%) with moderate hearing levels, $12(10 \%)$ with moderately severe hearing levels and $1(0.8 \%)$ with severe hearing levels. As results are showing that out of $125(100 \%) 111(86 \%)$ were diagnosed at some level of hearing loss variance in percentage and severity and only $14(11 \%)$ of $125(100 \%)$ had normal hearing so there is a strong influence of noise in developing noise induced hearing loss in textile mill workers. Out of $125(100 \%) 50$ (40\%) were diagnosed with low level of anxiety, 43(34\%) were diagnosed with moderate level of anxiety and $32(26 \%)$ were diagnosed with severe level of anxiety. All the participants working in the textile mill were facing some level of anxiety variance by the degree and percentage depending upon their degree of hearing loss.

\begin{tabular}{|l|c|c|}
\hline \multicolumn{1}{|c|}{ Option } & Frequency & Percent \\
\hline Normal & 14 & 11.2 \\
\hline Mild & 28 & 22.4 \\
\hline Mild-Moderate & 36 & 28.8 \\
\hline Moderate & 34 & 27.2 \\
\hline Moderate-Severe & 12 & 9.6 \\
\hline Severe & 1 & .8 \\
\hline Total & 125 & 100.0 \\
\hline
\end{tabular}

Table-I. Frequency of degree of hearing loss.

Figure-1 shows that Out of 125(100\%) 50 (40\%) were diagnosed with low level of anxiety, 43(34\%) were diagnosed with moderate level of anxiety and $32(26 \%)$ were diagnosed with severe level of anxiety. All the participants working in the textile mill were facing some level of anxiety variance by the degree and percentage depending upon their degree of hearing loss.

Table-Il shows that Total sample consisted of
125 individual in whom there were 41 individuals have 5-6 years' working experience majority of the individual (10) were in the moderately severe range (9) individuals were in moderate hearing loss range (8) in mild to moderate range and (8) in mild range and only (5) in normal range and individuals have 7- 8 years working (56) in which majority of individuals $(16+16)$ were in mild to moderate and moderately severe range respectively $(5+5)$ in mild and normal range and only (4) in in severe range, (24) Individuals have more than 8 years working experience in whom (6) individuals were in moderate range, (5) in severe range, (2) in mild range and $(4+4)$ in normal and mild to moderate range respectively. Chi square shows there is no correlation in working experience and hearing loss.

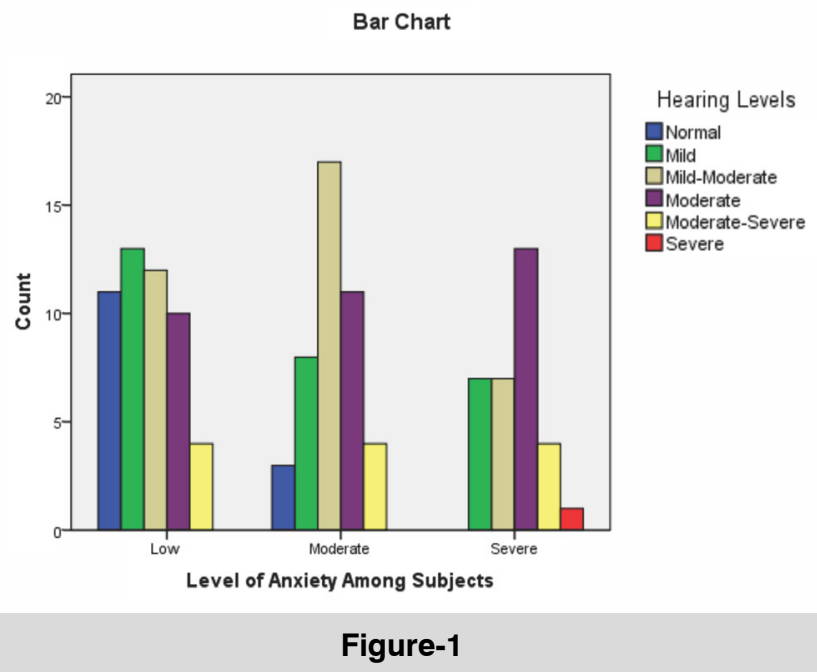

Table-III shows that 125 individual in whom there were 42 individuals have 5-6 years' working experience majority of the individual (19) were in the moderate level of anxiety (16) individuals were in low level of anxiety (7) in severe range and (59) individuals have 7- 8 years working experience in which majority of individuals (29) were in low level of anxiety (17) individuals have severe level of anxiety and (5) individuals have low level of anxiety, (24) Individuals have more than 8 years working experience in whom (42) individuals were in moderate level of anxiety, (32) have severe level of anxiety and (50) individuals have low level of anxiety. Chi square results shows there is strong correlation in working experience and level of anxiety as the level of significance is 
0.026 .

Table-IV shows to determine the association between anxiety and noise induced hearing loss in textile mill workers Pearson Chi square was used. $P$ value was calculated as .039 which is less than $5 \%$ which shows that results are significant. Out of 50 individuals with low level of anxiety $11(78.6 \%)$ have normal hearing level, $13(46.4 \%)$ mild degree, $12(33.3 \%)$ mild to moderate, 10(29.4\%) moderate, 4(33.3\%) moderately severe hearing level. Out of 43 Individuals having moderate level of anxiety $3(21.4 \%)$ have normal hearing, 8(28.6\%) mild hearing level, 17(47.2\%) in mild to moderate range, $11(32.4 \%)$ in moderate range, $4(33.3 \%)$ moderately severe hearing level range and out of 32 individual having severe level of anxiety $7(25.0 \%)$ individuals have mild hearing loss, $7(19.4 \%)$ mild to moderate range, $13(38 \%)$ in moderate hearing level range, 4 (33.3\%) in moderately severe range and only 1 in severe hearing loss range.

\section{DISCUSSION}

An analytical cross-sectional study was conducted on a group of 125 textile mill workers. They were evaluated clinically, audio logically and interviewed personally to fill Beck Anxiety Inventory developed by Beck in 1988 in a journal of consulting and clinical psychology, 56,893897. To our knowledge this scale was moderately correlated with the revised Hamilton rating scale (0.51) and mildly correlated with the Hamilton Depression scale.

\begin{tabular}{|c|c|c|c|c|c|c|c|}
\hline \multirow{2}{*}{$\begin{array}{l}\text { Experience of the } \\
\text { mill workers }\end{array}$} & \multicolumn{6}{|c|}{ Hearing Loss in Both Ears } & P-Value \\
\hline & Normal & Mild & Mild-Moderate & Moderate & Moderate-Severe & Severe & \multirow{5}{*}{.324} \\
\hline $5-6$ years & 5 & 8 & 8 & 9 & 10 & 2 & \\
\hline $7-8$ years & 5 & 5 & 16 & 13 & 16 & 4 & \\
\hline more than 8 years & 4 & 2 & 4 & 6 & 3 & 5 & \\
\hline Total & 14 & 15 & 28 & 28 & 29 & 11 & \\
\hline
\end{tabular}

Table-II. Experience of the mill workers * Hearing Loss in Both Ears Cross tabulation.

\begin{tabular}{|l|c|c|c|c|}
\hline $\begin{array}{c}\text { Experience of } \\
\text { the mill workers }\end{array}$ & $\mathbf{0 0}$ & \multicolumn{2}{|c|}{$\begin{array}{c}\text { Level of Anxiety Among Subjects } \\
\text { Moderate }\end{array}$} & Severe \\
\hline 5-6 years & 0 & 16 & 19 & 7 \\
\hline 7-8 years & 0 & 29 & 13 & 17 \\
\hline more than 8 years & 1 & 5 & 10 & 8 \\
\hline Total & 1 & 50 & 42 & 32 \\
\hline
\end{tabular}

Table-III. Experience of the mill workers * Level of anxiety among subjects cross tabulation.

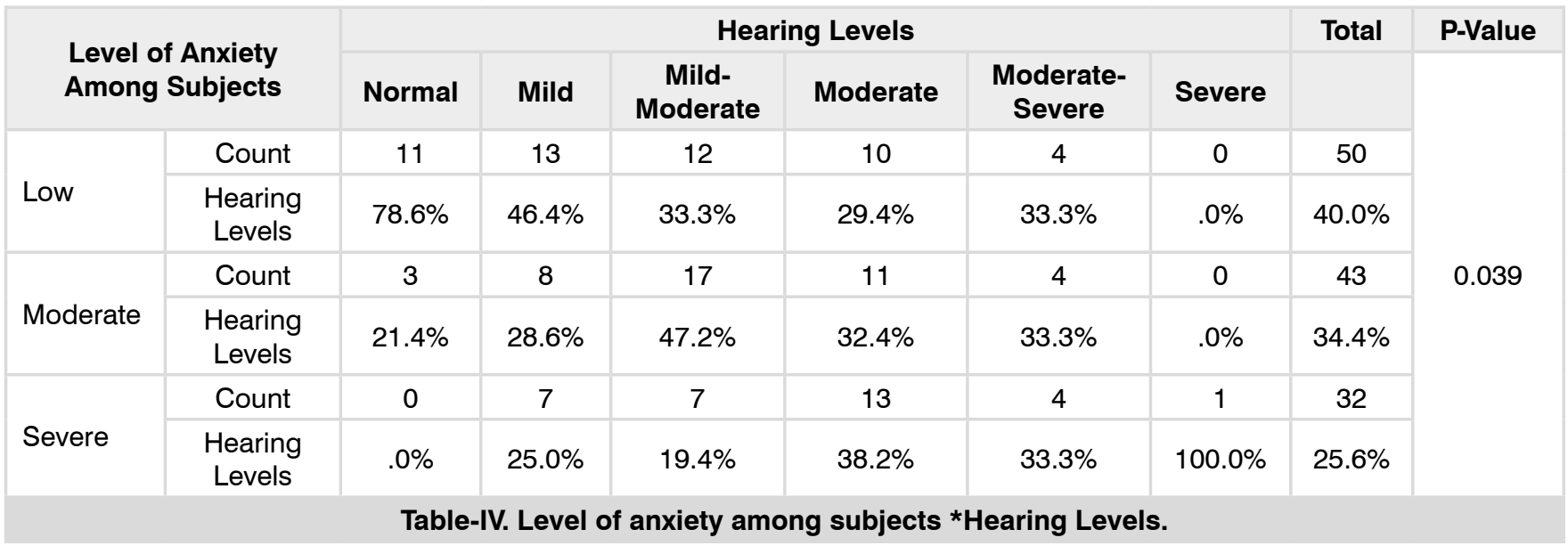


In a previous study which was titled as "Moderate Effects of Hearing Loss in Mental Health and Subjective well-being". ${ }^{16}$ The purpose of the study was to estimate effects of hearing loss on symptoms of anxiety, depression, self-esteem and subjective well-being. In this study a normal population sample of 50398 subjects of age 20 to 101 yearsinnord-trondelag completedaudiometric tests and questionnaire. The association between hearing loss and mental health was assessed with multiple linear regression analysis controlling for social background variables. Results shows effect of hearing loss were mostly significant but moderate in strength. Effects were stronger among young 20 to 44 years and middle age 45 to 64 years than among older 65 plus years. Loss of high and middle frequency of hearing had no effects on mental health measures if low frequency hearing was not also impaired the strongest observed effects was a change of 0.1 SD in mental health per $10 \mathrm{~dB}$ hearing loss. It was concluded that hearing loss is associated with substantially reduced mental health rating among some young and middle age persons but usually does not affects mental health much among older persons. ${ }^{17}$

This study shows an association of mental health (anxiety, depression and stress) with hearing impairment. Present study also based on the purpose to find out the frequency of noise induced hearing loss in textile mill workers and to find out correlation between severity levels of anxiety (a substantial part of mental health) with severity levels of noise induced hearing loss. ${ }^{18}$ In this study the severity of hearing loss increases from normal hearing to profound hearing loss and it is significantly correlated with the severity of anxiety starting from low, to severe considering $P$ value less than 5. Textile mill workers of age 25 to 40 years working in noisy environment have more exposure to noise due to work environment which can lead to develop noise induced hearing loss of different severity levels assessed by Audiological evaluation along with the hearing loss they also develop some level of anxiety (low to severe) which affects them in terms of anxiety symptoms like Numbness, Hotness, fear, anger, which were assessed by interviewing them by Beck anxiety inventory which shows a significant correlation between developing hearing impairment ranging from normal to profound level of Noise induced hearing and levels of anxiety as shown in Table-I,III in results. ${ }^{19}$ Present study advocated the previous study titled as "Moderate Effects of Hearing Loss in Mental Health and Subjective well-being" that there Is an association between Mental health and hearing impairment and it also justify the objectives that there is greater frequency of noise induced hearing loss in textile mill workers and there is significant correlation between Noise induced hearing loss and anxiety in textile mill workers. ${ }^{20}$

The study conducted that noise is a genuine word related to health risk in the material production line which was contemplated. The significant hazard factors for NIHL were the term and the degree of noise introduction. This relationship is like that saw in past investigations in Thailand and Egypt The higher disorder levels in the weaving and spinning areas, reflected in higher disorders of NIHL among laborers in those segments, have likewise been reported by past investigations in different nations. Despite the fact that the rejection measures are the equivalent with different examinations and permit equivalence of discoveries, they can possibly cause underestimation of the NIHL level. The "solid laborer impact" could likewise be associated with causing underestimation of the NIHL level since there is no efficient wellbeing administrations for word related medical issues in the manufacturing plant. This implies laborers experiencing serious hearing misfortune may have left the production line, leaving moderately solid specialists in the industrial facility. In which case, the NIHL gauge from a cross-sectional study would think little of the genuine greatness of the issue. This proposes the real NIHL level could be higher than what was seen in this examination. Weavers and spinners in the production line were presented to average degrees of disorder over $85 \mathrm{~dB}(\mathrm{~A})$, as far as possible worth set by numerous mechanical nations in Europe and Joined States (17) just as in some African nations, including Zimbabwe (19) and Kenya (20). The noise level of about $100 \mathrm{~dB}$ $(A)$ in the weaving segment is practically identical 
to the $99.5 \mathrm{~dB}(\mathrm{~A})$ level estimated in weaving areas of material factories in Asmara (9), $102.5 \mathrm{~dB}(\mathrm{~A})$ in Hong Kong (18), $101.3 \mathrm{~dB}(\mathrm{~A})$ in Thailand (17), $100 \mathrm{~dB}(\mathrm{~A})$ in Egypt $(16,21)$, and 99-102 dB(A) in a jute weaving factory in the UK (22). ${ }^{21}$

Based on the study findings, application of hearing conservation program through expansion and enforcement of regulations to identify and monitor occupational risk groups, and restriction of importation of equipment which emits dangerous levels of noise are recommended. ${ }^{22}$ In addition, engineering modifications of buildings and machinery to reduce noise levels, and promotion of safety and health programmes, including promotion of workers' awareness on self-protective measures, such as the use of personal protective device (PPD), should be considered. ${ }^{23,24}$

\section{CONCLUSION}

The findings of the study support my argument by statistical data. The mill workers are on the risk of developing hearing loss of different severity levels which also cause anxiety to them. It can highly affect their interpersonal, social, and professional life.

\section{Copyright@ 25 May, 2021.}

\section{REFERENCES}

1. Adadey SM, Awandare G, Amedofu GK, Wonkam A. Public health burden of hearing impairment and the promise of genomics and environmental research: A case study in Ghana, Africa. Omics: A journal of integrative biology. 2017 Nov 1; 21(11):638-46.

2. Akande TM, Owoyemi JO. Awareness and attitude to social and health hazards from generator use in Ayigba, Nigeria. Medwell Journal. Research Journal of Medical Sciences. 2008; 2(4):185-9.

3. Chung SD, Hung SH, Lin HC, Sheu JJ. Association between sudden sensorineural hearing loss and anxiety disorder: A population-based study. European Archives of Oto-Rhino-Laryngology. 2015 1; 272(10):2673-8.

4. Shahid A, Jamali T, Kadir MM. Noise induced hearing loss among an occupational group of textile workers in Karachi, Pakistan. Occupational medicine \& health affairs. 2018; 6(4).
5. Osibogun A, Igweze IA, Adeniran LO. Noise-induced hearing loss among textile workers in Lagos metropolis. Niger Postgrad Med J 2000; 7(3):104-1.

6. Halvani gh, zare $\mathrm{m}$, barkhourdari a. Noise induced hearing loss among textile workers of Taban factories in Yazd. 2009; 8(6):69-74.

7. Ghotbi M, Monazzam M, Khanjani N, Halvani G, Salmani Nodoushan M, Jafari Nodoushan R. Survey of noise exposure and permanent hearing loss among shadris spinning factory workers of Yazd using Task Base Method (TBM). Iran Occupational Health. 2011 Dec 15; 8(3):4-0.

8. Ripke S, O’Dushlaine C, Chambert K, Moran JL, Kähler AK, Akterin S, Bergen SE, Collins AL, Crowley JJ, Fromer M, Kim Y. Genome-wide association analysis identifies $\mathbf{1 3}$ new risk loci for schizophrenia. Nature genetics. 2013 Oct; 45(10):1150.

9. Fuente A, Hickson L. Noise-induced hearing loss in Asia. International Journal of Audiology. 2011 Mar 1; 50(sup1):S3-10.

10. Mehrparvar AH, Mirmohammadi SJ, Ghoreyshi A, Mollasadeghi A, Loukzadeh Z. High-frequency audiometry: A means for early diagnosis of noiseinduced hearing loss. Noise and Health. 2011 1; 13(55):402.

11. Le TN, Straatman LV, Lea J, Westerberg B. Current insights in noise-induced hearing loss: A literature review of the underlying mechanism, pathophysiology, asymmetry, and management options. Journal of Otolaryngology-Head \& Neck Surgery. 2017 Dec; 46(1):1-5.

12. Reed NS, Altan A, Deal JA, Yeh C, Kravetz AD, Wallhagen $M$, Lin FR. Trends in health care costs and utilization associated with untreated hearing loss over 10 years. JAMA Otolaryngology-Head \& Neck Surgery. 2019 Jan 1; 145(1):27-34.

13. Lawrence BJ, Jayakody DM, Bennett RJ, Eikelboom $R H$, Gasson N, Friedland PL. Hearing loss and depression in older adults: a systematic review and metaanalysis. The Gerontologist. 2020 Apr 2; 60(3):e137-54.

14. Ching TY, Dillon $H$, Button $L$, Seeto $M$, Van Buynder $P$, Marnane V, Cupples L, Leigh G. Age at intervention for permanent hearing loss and 5-year language outcomes. Pediatrics. 2017 Sep 1; 140(3).

15. Goman AM, Reed NS, Lin FR. Addressing estimated hearing loss in adults in 2060. JAMA OtolaryngologyHead \& Neck Surgery. 2017 Jul 1; 143(7):733-4. 
16. Lyubomirsky S, King L, Diener $E$. The benefits of frequent positive affect: Does happiness lead to success?. Psychological bulletin. 2005 Nov; 131 (6):803.

17. Carmen $R$, Uram S. Hearing loss and anxiety in adults. The Hearing Journal. 2002 Apr 1; 55(4):48-50.

18. Nelson DI, Nelson RY, Concha $\square$ Barrientos M, Fingerhut $M$. The global burden of occupational noise $\square$ induced hearing loss. American journal of industrial medicine. 2005; 48(6):446-58.

19. Deal JA, Reed NS, Kravetz AD, Weinreich H, Yeh C, Lin FR, Altan A. Incident hearing loss and comorbidity: A longitudinal administrative claims study. JAMA Otolaryngology-Head \& Neck Surgery. 2019 Jan 1; 145(1):36-43.

20. Uchida $Y$, Sugiura S, Nishita Y, Saji N, Sone M, Ueda H. Age-related hearing loss and cognitive decline-The potential mechanisms linking the two. Auris Nasus Larynx. 2019 Feb 1; 46(1):1-9.
21. Ford AH, Hankey GJ, Yeap BB, Golledge J, Flicker L, Almeida OP. Hearing loss and the risk of dementia in later life. Maturitas. 2018 Jun 1; 112:1-1.

22. Davisa AC, Hoffmanb HJ. Hearing loss: Rising prevalence and impact. Bull World Health Organ. 2019 Oct 1; 97:646-A.

23. Presacco A, Simon JZ, Anderson S. Speech-in-noise representation in the aging midbrain and cortex: Effects of hearing loss. Plos one. 2019 Mar 13; 14(3):e0213899.

24. Carroll $\mathrm{YI}$, Eichwald J, Scinicariello F, Hoffman HJ, Deitchman S, Radke MS, Themann CL, Breysse P. Vital signs: Noise-induced hearing loss among adultsUnited States 2011-2012. MMWR. Morbidity and mortality weekly report. 2017 Feb 10; 66(5):139.

\begin{tabular}{|c|c|c|c|}
\hline \multicolumn{4}{|c|}{ AUTHORSHIP AND CONTRIBUTION DECLARATION } \\
\hline No. & Author(s) Full Name & Contribution to the paper & Author(s) Signature \\
\hline 1 & Azmat Tahira & Write-up \& Data Collection. & A2nati. \\
\hline 2 & Atia-Ur-Rehman & Critical Review. & phiakefur \\
\hline 3 & Tahira Ashraf & Discussion. & $\begin{array}{l}\text { TAHIPA } \\
\text { ASHRAP }\end{array}$ \\
\hline 4 & Waris Ali & Data Collection. & waris \\
\hline 5 & Ambreen Sadaf & Statistical Analysis. & 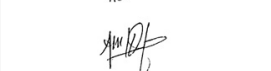 \\
\hline 6 & Taimoor Hassan & $\begin{array}{l}\text { Statistical Analysis, Final } \\
\text { Editing \& review. }\end{array}$ & cauticleon? \\
\hline
\end{tabular}

